\title{
The language of the Bilhoola in British Columbia.
}

The Bilhoola tribe inhabits the district of Dean Inlet and Bentinok Arm, and is surrounded by tribes of the Kwakiool family. Their language, as those of the neighboring tribes, is very little known: therefore the following remarks, imperfect though they be, may be of interest. The material was collected by me from some individuals of this tribe who were brought to Germany by Capt. A. Jacobson, and staid for a fortnight at Berlin.

The most remarkable peculiarity of the language is, that words in connection cannot be expressed except by the belp of certain prefixes much resembling an article. The most common of these are $t i$ and $u a$. For instance: 'large,' shg (sh pronounced almost like $c h$ in the German ich); 'stone,' t'ht (h like $c h$ in the Scotch loch); ' large stone,' ti shg ti t'ht.

The plural of nouns is formed in different ways, either by reduplication of the initial sound or by the ending uks. In some instances I found $p i$ and $t j$. Frequently the singular serves also for the plural. It seems that the cases are only expressed by the position of the word in the sentence.

The personal pronoun is -

SINGULAR.

$\begin{array}{lll}1 s t & \text { person, ens } \\ 2 d & \text { " } & \text { ino } \\ 3 d & \text { " } & \text { t 'aish }\end{array}$

The possessive pronoun is formed in two ways : it is either derived from the personal pronoun, and connected with the noun by $t i$ in the singular, and $u \alpha$ in the plural (for instance: enstl 'ti t'nah, 'my head;' th 'mitl 'ua sotl', 'our house'), or it is expressed by a suffix ( $t$ 'nah-stsh, 'my head;' sotl' $t l s h$, 'our house').

The flexion of the verb is quite remarkable. It is either formed by a personal pronoun and the stem of the verb, both being connected by $t i$ or some other prefix, or by suffixes. Besides, the pronoun can be repeated after the verb : for example, -

$$
\left.\begin{array}{l}
\text { ens } t i \text { tl 'ap } \\
\text { th'apsts } \\
\text { th'apsts ti ens }
\end{array}\right\} \text { 'I go.' }
$$

The suffixes are identical with the possessive suffixes of the noun.

The objective flexion of the verb bears the features of having originated by agglutination of the pronoun to the verb: for example, $k s h$ ', sh sino, 'I see you ;' ksh 'sh titl,' 'We see them.'

I could not find any distinct traces of the tenses being expressed by suffixes or by prefixes. An iterative is formed by the prefix $a t l^{\prime} ;$ a locative, by $n u$.

The principal colors are red, yellow, and blue, the limit between the latter two being indefinite. Green is sometimes called yellow, sometimes blue; viz., similar to the one or the other.

The names of the numbers are formed according to the quinary-vigesimal system : 6 is $5+1: 11$ is 10 $+1 ; 20$, one man, i.e., the number of fingers and toes ; 40 , two men, etc.

The vocabulary bears only a very slight resemblance to that of the Kwakiool and the Selish. As far as I know, the grammar much resembles that of the Bilballa.

The traditions and customs of this people are almost identical with those of the Tlinkit and their other neighbors, though in their details there may be some differences.

Franz Boas.

Berlin, Feb. 5.

\section{Discomforts arising from sponge spicules in pond- soils.}

Near Monticello, in this state, are numerous ponds and sloughs, many of which have been drained and brought under cultivation. The soil is of the typical humus character, containing no clay and but very little sand. For ages, perhaps, each summer has produced its rank growth of aquatic plants, and each autumn has laid this growth beneath the rippling surface of the pond, to be protected from thorough decomposition by its waters: consequently, when the hand of improvement removes the water, a rich bed of vegetable matter is brought to the sun and air. Such situations are peculiarly favorable for the cultivation of corn, and large yields may be produced; but in the cultivation of the crop a most annoying difficulty is encountered. In bright, warm days, the workmen in these fields experience a distressing itching in those parts of the body where there is rubbing or chafing of the boots or clothing. I cannot better describe this sensation than by comparing it with the pain occasioned by the attack of a flock of mosquitoes upon the affected parts. It is almost unbearable, and some persons are obliged to stop work and seek relief. Usually by taking a bath and cooling the body the irritation ceases; but, if it again be heated by over-exertion, the pain is renewed. Such a condition will last for about two days.

On microscopic examination, we found among the particles of sand and vegetable matter numerous spindle-shaped, sharp-pointed bodies. Some were hooked and curved; some broken in the middle, making one end blunt; some were covered thickly with spines. These have been identified as diatoms and fresh-water sponge spicules. The bodies are of a siliceous character, for they are not destroyed by ignition, nor attacked by hydrochloric acid. Since fresh-water sponges are quite abundant in many ponds, their remains form a conspicuous part of the soil.

Having thus ascertained the cause of the irritation, it is not difficult to understand its production. A fine impalpable dust always rises from the soil when it is being cultivated. This penetrates the clothing, and finds its way to those parts of the body where there is friction between the skin and clothing. The backward and forward motion of the cloth causes the spicules to work their way into the skin far enough to irritate the nerves and produce the pain. The increased circulation due to active exercise increases the sensitiveness of the skm, and bence the pain is greater under such conditions.

No remedy has as yet suggested itself. The best preventive is wearing such clothing as will most nearly exclude the dust. As the spicules are composed of one of the most enduring substances, they will not be removed from the soil by the usual changes taking place in it. Wind and cultivation may disseminate them so that they will be far less troublesome, but it will be a slow process. Altogether, the outlook for the comfortable cultivation of these pond-soils is not encouraging; and, if the large crops which they are capable of producing are obtained, much annoyance and inconvenience must be endured.

Purdue university, Lafayette, Ind.

S. T. VIRDEN 